\title{
Avaliação nutricional do capim-elefante (Cameroon) em diferentes idades de rebrotação ${ }^{1}$
}

\author{
Polyana Albino Silva Machado ${ }^{2}$, Sebastião de Campos Valadares Filho ${ }^{3}$, Rilene Ferreira \\ Diniz Valadares ${ }^{4}$, Edenio Detmann ${ }^{3}$, Mônica Lopes Paixão ${ }^{2}$, Douglas dos Santos Pina ${ }^{2}$
}

\author{
1 Pesquisa parcialmente financiada pela FAPEMIG. \\ 2 Programa de Pós-graduação em Zootecnia/UFV. \\ ${ }^{3}$ DZO/UFV \\ ${ }^{4}$ DVTIUFV.
}

RESUMO - Objetivou-se determinar o consumo e as digestibilidades aparente total, ruminal e intestinal de matéria seca (MS) e seus componentes: matéria orgânica (MO), proteína bruta (PB), extrato etéreo (EE), fibra em detergente neutro (FDN) e carboidratos não-fibrosos (CNF) do capim-elefante em diferentes idades de rebrotação e quantificar a produção de proteína microbiana. Utilizaram-se quatro novilhos mestiços, fistulados no rúmen e abomaso, alimentados à vontade com capim-elefante e sal mineral. O experimento foi avaliado considerando-se o grupo de animais como uma amostra aleatória simples, sendo os períodos de avaliação correspondentes às idades crescentes de rebrotação (33, 48, 63, 78 e 93 dias) e cada animal como medidas repetidas. Os consumos de matéria seca (MS), nutrientes digestíveis totais (NDT) e as digestibilidades totais dos demais nutrientes diminuíram linearmente com o aumento da idade de rebrotação. Os teores de MO, CNF e FDN apresentaram máximos consumos aos 44,43; 51,05 e 60,50 dias de rebrotação, respectivamente. O mínimo consumo de PB ocorreu aos 94,27 dias de rebrotação do capim. As digestibilidades ruminais da MS e MO aumentaram linearmente com o avanço da idade. Os compostos nitrogenados microbianos sofreram redução linear com o aumento da idade do capim-elefante. Recomenda-se usar o capim-elefante com idade entre 30 e 35 dias de rebrotação, quando se observou maior valor nutritivo da planta.

Palavras-chave: consumo, digestibilidade parcial, digestibilidade total, nutrientes, volumoso

\section{Nutritional evaluation of elephantgrass at different regrowth ages}

\begin{abstract}
The objective of this trial was to determine the intake and the total, ruminal and intestinal apparent digestibilidade of dry matter (DM) and its components: organic matter (OM), crude protein (CP), ether extract (EE), in neutral detergent fiber (NDF) and no-fiber carbohydrates (NFC) of the elephantgrass in different regrowth ages and to quantify the microbial protein production. Four crossbred steers fitted with ruminal and abomasal cannula were fullfed with elephantgrass and mineral salt. The experiment was evaluated considering the group of animals as simple random sample, being the corresponding periods of evaluation to the increasing regrowth ages (33, 48, 63, 78 and 93 days) and each animal as repeated measures. Intakes of dry matter (DMI) and total digestible nutrients (TDN) and total digestibilities of the others nutrients linearly decreased as days of regrowth ages increased. The content of OM, NFC and NDF presented maximum intake at 44.43, 51.05, and 60.50 days of regrowth ages, respectively. The minimum CP intake was at 94.27 days of regrowth ages. The ruminal digestibilities of DM and OM linearly increased as days of regrowth ages increased. Microbial protein yield linearly reduced as days of regrowth age increased. The microbial nitrogenous compounds also showed a linear reduction with the increase of the days of regrowth ages of elephantgrass. It is recommended to use elephantgrass between 30 and 35 days of regrowth ages, when it observed greater nutritional value of the plant.
\end{abstract}

Key Words: intake, nutrients, partial digestibility, roughage, total digestibility

\section{Introdução}

O capim-elefante é bastante utilizado no Brasil para alimentação dos ruminantes, mas, dentro de um período de tempo relativamente curto, esta gramínea pode perder seu valor nutritivo, tornando-se muito fibrosa e pouco digestível, energeticamente deficiente.

A ingestão de matéria seca (MS) é o fator mais importante na nutrição, pois estabelece as quantidades de nutrientes disponíveis para a saúde e a nutrição animal (NRC, 2001). 
Conrad et al. (1964) relataram que o controle do consumo de alimentos é explicado com base em dois mecanismos: o físico e o fisiológico. Mertens (1994) acrescentou que a ingestão de MS também é controlada por fatores psicogênicos. O mecanismo físico refere-se à distensão física do rúmen-retículo; o fisiológico é regulado pelo balanço energético; e a regulação psicogênica envolve o comportamento do animal influenciado por fatores inibidores ou estimuladores presentes no próprio alimento.

Além de conhecer a composição bromatológica e a ingestão de alimentos, é importante também saber sobre a utilização dos nutrientes pelo animal, que é obtida por meio de estudos de digestão. Saber os locais de digestão dos nutrientes é essencial, pois permite calcular as quantidades absorvidas nos diferentes segmentos do trato digestivo.

As exigências protéicas dos ruminantes são atendidas pelos aminoácidos que chegam ao intestino delgado, os quais são provenientes, principalmente, da proteína microbiana sintetizada no rúmen e da proteína dietética nãodegradada no rúmen (NRC, 2001). Uma vez que a maior parte do nitrogênio que chega ao intestino delgado é de origem microbiana, fica evidente que a eficiência de crescimento microbiano tem grande impacto na nutrição de ruminantes (Russell et al., 1992).

A eficiência de síntese microbiana tem sido expressa de diferentes formas: em função dos nutrientes digestíveis totais (NDT), (NRC, 1989 e 2001), da matéria orgânica degradada no rúmen (MODR) (ARC, 1984), da energia metabolizável fermentável da dieta (AFRC, 1993) ou dos carboidratos totais degradados no rúmen (CHODR), segundo o Cornell Net Carboydrate and Protein System -(CNCPS), descrito por Russell et al. (1992).

Perez et al. (1996) verificaram que a excreção de derivados de purinas pode constituir método simples e nãoinvasivo para estimar a produção de proteína microbiana no rúmen. A excreção de derivados de purinas está diretamente relacionada à absorção de purinas e ao conhecimento da relação $\mathrm{N}$-purinas: $\mathrm{N}$-total na massa microbiana. A absorção de $\mathrm{N}$ microbiano pode ser calculada a partir da quantidade de purinas absorvida, que é estimada a partir da excreção urinária dos derivados de purinas (Chen \& Gomes, 1992).

Conduziu-se este trabalho com o objetivo de avaliar o efeito das diferentes idades de rebrotação do capimelefante sobre o consumo, as digestibilidades aparente total, ruminal e intestinal dos nutrientes e a produção microbiana.

\section{Material e Métodos}

O experimento foi conduzido no Laboratório de Animais e no Laboratório de Nutrição Animal do Departamento de Zootecnia do Centro de Ciências Agrárias da Universidade Federal de Viçosa, no período de novembro de 2002 a fevereiro de 2003.

A cidade de Viçosa, localizada na Zona da Mata do Estado de Minas Gerais, tem como coordenadas geográficas de posição 2045'20" de latitude sul e 4552'40" de longitude oeste de Greenwich e altitude de $657 \mathrm{~m}$. A temperatura média e a precipitação pluviométrica observadas nos anos de 2000 e 2001 foram, respectivamente, de $20^{\circ} \mathrm{C}$ e $1.217,9 \mathrm{~mm}$ e 20,7 ${ }^{\circ} \mathrm{Ce} 1.148 \mathrm{~mm}$ (UFV, 2002).

Foram utilizados quatro novilhos mestiços, castrados, com peso corporal (PC) médio de $320 \mathrm{~kg}$, fistulados no rúmen e abomaso, segundo as técnicas descritas por Leão \& Coelho da Silva (1980). Os animais foram mantidos em regime de confinamento, alojados em baias individuais cobertas ( $3 \times 3 \mathrm{~m})$, com piso de concreto revestido de borracha, comedouros de alvenaria, bebedouros individuais e cochos adaptados para o fornecimento de sal mineral.

Foi utilizada capineira com capim-elefante (Pennisetum purpureum Schum.) cv. Cameroon, freqüentemente exposta à adubação orgânica, submetida a um corte de uniformização em 31/10/2002 e imediatamente adubada com $500 \mathrm{~kg}$ de adubo granulado 20-05-20 (NPK) por ha.

O experimento foi dividido em cinco períodos experimentais, nos quais se utilizou, seqüencialmente, o capim-

Tabela 1 - Teores dos nutrientes do capim-elefante em diferentes idades de rebrotação

\begin{tabular}{lrrrrr}
\hline Item & \multicolumn{5}{c}{ Dias de rebrotação } \\
\cline { 2 - 6 } & \multicolumn{1}{c}{33} & \multicolumn{1}{c}{48} & \multicolumn{1}{c}{63} & \multicolumn{1}{c}{78} & \multicolumn{1}{c}{93} \\
\hline MS (\%) & 9,20 & 9,71 & 13,46 & 15,51 & 17,51 \\
MO $^{1}$ & 86,52 & 86,54 & 88,48 & 89,70 & 89,64 \\
PB $^{1}$ & 14,10 & 9,20 & 7,80 & 5,32 & 5,18 \\
NNP $^{2}$ & 37,25 & 38,86 & 30,28 & 26,12 & 20,07 \\
PIDN $^{2}$ & 34,50 & 35,81 & 47,54 & 47,01 & 39,17 \\
PIDA $^{2}$ & 11,03 & 15,23 & 14,82 & 18,64 & 16,68 \\
EE $^{1}$ & 2,78 & 2,09 & 2,11 & 2,28 & 2,42 \\
FDN $^{1}$ & 60,62 & 63,47 & 67,68 & 69,58 & 69,23 \\
FDNcp $^{1}$ & 53,77 & 58,80 & 61,87 & 65,44 & 64,97 \\
CNF $^{1}$ & 10,51 & 12,17 & 10,93 & 13,26 & 12,81 \\
CNF $^{1}$ cp & 17,36 & 16,84 & 16,74 & 17,40 & 17,07 \\
NDT $^{1}$ & 68,89 & 64,04 & 58,50 & 58,68 & 55,22 \\
FDA $^{1}$ & 39,23 & 40,69 & 43,93 & 45,53 & 47,11 \\
FDAi $^{1}$ & 15,45 & 16,81 & 18,22 & 19,68 & 32,74 \\
Lignina $^{1}$ & 5,67 & 6,08 & 6,42 & 6,48 & 6,66 \\
\hline
\end{tabular}

$1 \%$ da MS; ${ }^{2} \%$ da PB.

NNP - nitrogênio não-protéico, PIDN - proteína insolúvel em detergente neutro, PIDA - proteína insolúvel em detergente ácido. 
elefante nas seguintes idades de rebrotação: 33, 48, 63, 78 e 93 dias. A média de cada idade de rebrotação foi calculada considerando-se um período de coletas de fezes e digesta abomasal com duração de seis dias. Dessa forma, a idade média de 33 dias foi obtida quando as plantas apresentavam entre 30 e 35 dias de rebrotação.

A dieta foi fornecida à vontade, em duas refeições diárias, às 7 e $15 \mathrm{~h}$, permitindo-se $5 \%$ de sobras. O capim-elefante (Tabela 1) foi cortado imediatamente antes de ser ofertado. Água e o sal mineral também foram fornecidos à vontade.

O óxido crômico foi utilizado na determinação da digestibilidade, sendo introduzido através da fístula ruminal, em um única dose diária de $15 \mathrm{~g}$, durante cinco dias antes do início da cada período de coletas e nos seis dias de coletas, sempre às $12 \mathrm{~h}$.

As coletas de fezes e digesta de abomaso foram feitas uma vez ao dia, com intervalo de coletas de 22 horas (no primeiro dia, coleta às $18 \mathrm{~h}$ e no sexto dia, às $8 \mathrm{~h}$ ). As amostras, imediatamente após a coleta, foram pré-secas em estufa de ventilação forçada regulada para $60^{\circ} \mathrm{C}$, por 72 a 96 horas, e processadas em moinho com peneira de malha de $1 \mathrm{~mm}$, sendo então elaborada uma amostra composta por animal e por período com base no peso seco de cada amostra diária. As amostras compostas foram devidamente acondicionadas em recipientes de vidro e, posteriormente, submetidas às análises laboratoriais. Foi coletada (durante os seis dias) alíquota de $10 \mathrm{~mL}$ diários de fluido abomasal, que foi armazenada, in natura, em vidros e, depois, acondicionadas a $-5^{\circ} \mathrm{C}$ para proceder-se à determinação do $\mathrm{N}$ amoniacal ( $\mathrm{N}-\mathrm{NH}_{3}$ ), conforme técnica descrita por Fenner (1965) adaptada por Vieira (1980).
A matéria seca (MS), matéria orgânica (MO), nitrogênio total e extrato etéreo (EE) foram determinados conforme técnicas descritas por Silva \& Queiroz (2002), sendo a proteína bruta $(\mathrm{PB})$ obtida pelo produto entre o teor de nitrogênio total e o fator 6,25. Os teores de fibra em detergente neutro (FDN) e FDN corrigida para cinzas e proteína (FDNcp) foram determinados em todas as amostras, de acordo com Pell \& Schofield (1993), utilizando-se o método da autoclave, segundo descrição de Rennó et al. (2002). As análises de cromo nas fezes e nas digestas de abomaso foram realizadas de acordo com a técnica proposta por Willians et al. (1962), citados por Silva \& Queiroz (2002). Nos alimentos, foram ainda analisadas as concentrações de fibra em detergente ácido (FDA), lignina e compostos nitrogenados insolúveis em detergente neutro (NIDN) e em detergente ácido (NIDA), seguindo as técnicas descritas por Silva \& Queiroz (2002).

Os compostos nitrogenados não-protéicos (NNP) foram determinados utilizando-se a metodologia descrita por Broderick, em 1997 (comunicação pessoal), nas amostras de capim-elefante in natura, em que, aproximadamente, $10 \mathrm{~g}$ de amostra foram diluídos em $100 \mathrm{~g}$ de água destilada, processados no liquidificador por 30 segundos e filtrados em duas camadas de gaze. Posteriormente, uma alíquota de $20 \mathrm{~mL}$ do filtrado foi tratada com $5 \mathrm{~mL}$ de ácido tricloroacético a $25 \%$ (TCA - 25\%P/V), deixada em repouso por 30 minutos e, então, centrifugada a $30.000 \mathrm{x}$ g por 15 minutos. A partir de $2 \mathrm{~mL}$ do sobrenadante determinou-se o nitrogênio total (Silva \& Queiroz, 2002).

Os CNF foram calculados pela equação proposta por Hall etal. (1997): $\mathrm{CNF}=100-(\% \mathrm{~PB}+\% \mathrm{EE}+\%$ Cinzas $+\% \mathrm{FDNcp})$.

Tabela 2 - Consumos dos nutrientes, em função do período de rebrotação

\begin{tabular}{|c|c|c|c|c|c|c|c|c|c|}
\hline Item & \multicolumn{5}{|c|}{ Dias de rebrotação } & EPM & \multicolumn{3}{|c|}{ Valor - $\mathrm{P}^{1}$} \\
\hline & \multicolumn{5}{|c|}{ Consumo (kg/dia) } & & & & \\
\hline $\mathrm{MS}^{2}$ & 7,05 & 7,08 & 6,61 & 6,35 & 5,72 & 0,24 & 0,0005 & $<0,0001$ & 0,0968 \\
\hline $\mathrm{MO}^{3}$ & 6,21 & 6,23 & 6,04 & 5,82 & 5,11 & 0,22 & 0,0011 & 0,0001 & 0,0222 \\
\hline $\mathrm{PB}^{4}$ & 0,99 & 0,65 & 0,52 & 0,34 & 0,31 & 0,02 & $<0,0001$ & $<0,0001$ & $<0,0001$ \\
\hline $\mathrm{CNFcp}^{7}$ & 1,35 & 1,31 & 1,38 & 1,27 & 1,02 & 0,04 & $<0,0001$ & $<0,0001$ & 0,0001 \\
\hline \multirow[t]{2}{*}{$\mathrm{NDT}^{8}$} & 4,73 & 4,55 & 3,98 & 3,72 & 3,12 & 0,17 & $<0,0001$ & $<0,0001$ & 0,3735 \\
\hline & \multicolumn{5}{|c|}{ Consumo (\%PC) } & & & & \\
\hline $\mathrm{MS}^{9}$ & 2,16 & 2,13 & 1,96 & 1,85 & 1,65 & 0,07 & $<0,0001$ & $<0,0001$ & 0,1871 \\
\hline FDNcp $^{10}$ & 1,16 & 1,25 & 1,20 & 1,20 & 1,05 & 0,04 & 0,0079 & 0,0140 & 0,0041 \\
\hline
\end{tabular}

1 Dias = efeito geral do tempo (dias de rebrotação) sobre a variável; $L$ e Q = efeitos de ordens linear e quadrática relativos aos dias de rebrotação: ${ }^{2} \hat{Y}=7,9783-0,0225 X\left(r^{2}=0,9082\right) ;{ }^{3} \hat{Y}=5,32719+0,04175 X-0,00046984 X^{2}\left(r^{2}=0,9846\right) ;{ }^{4} \hat{Y}=1,90085-0,03382 X+0,00017937 X^{2}\left(r^{2}=0,9887\right) ;{ }^{5} \hat{Y}=0,06614$ $+0,000753 X\left(r^{2}=0,5431\right) ;{ }^{6} \hat{Y}=2,43610+0,05677 X-0,00046921 X^{2}\left(r^{2}=0,8465\right) ;{ }^{7} \hat{Y}=0,87672+0,01974 X-0,00019333 X^{2}\left(r^{2}=0,9063\right) ;{ }^{8} \hat{Y}=5,72182-0,02701 X$ $\left(r^{2}=0,9740\right) ;{ }^{9} \hat{Y}=2,49612-0,00871 X\left(r^{2}=0,9636\right) ;{ }^{10} \hat{Y}=0,82852+0,01462 X-0,00013111 X^{2}\left(r^{2}=0,8992\right)$. 
O teor de nutrientes digestíveis totais (NDT) foi calculado por: $\mathrm{NDT}=\mathrm{PBD}+2,25 \mathrm{EED}+\mathrm{FDNcpD}+\mathrm{CNFD}$, em que PBD, EED, FDNcpD e CNFD significam, respectivamente, proteína bruta digestível, extrato etéreo digestível, fibra em detergente neutro (isenta de cinzas e proteína) digestível e carboidratos não fibrosos digestíveis (Weiss, 1999).

Quatro horas após o fornecimento do alimento, no sexto dia do período de coletas, realizou-se coleta spot de urina, quando os animais urinaram espontaneamente. Uma amostra de $10 \mathrm{~mL}$ de urina foi diluída em $40 \mathrm{~mL}$ de ácido sulfúrico $0,036 \mathrm{~N}$, para evitar destruição bacteriana dos derivados de purina urinários e precipitação do ácido úrico (Broderick et al., 1992). Devidamente identificadas, as amostras foram armazenadas a $-15^{\circ} \mathrm{C}$ para posteriores análises laboratoriais.

A creatinina foi determinada nas amostras de urina com o uso de picrato e acidificante (kits comerciais - Labtest diagnóstica) e o volume urinário em 24 horas foi estimado a partir da divisão da excreção diária de creatinina (mg/dia) pela concentração de creatinina (mg/L). Considerou-se constante a excreção diária de creatinina e utilizou-se o valor de 24,04 mg/kg PC obtido por Valadares et al. (1997), em novilhos zebuínos.

Nas amostras de urina, também foram realizadas as análises dos derivados de purinas (alantoína e ácido úrico). A alantoína foi determinada pelo método colorimétrico, conforme técnica de Fujihara et al. (1987), descrita por Chen \& Gomes (1992). As concentrações de creatinina e ácido úrico na urina e uréia na urina e soro foram estimadas pelos métodos de Jaffé modificado (Bioclin K016-1), colorimétrico (UOD-PAP, Bioclin K052) e enzimático colorimétrico (Bioclin K047), respectivamente. A excreção de derivados de purinas (DP) na urina em 24 horas foi calculada multiplicando-se o volume urinário estimado em 24 horas pela concentração dos DP na amostra spot de urina.

As purinas microbianas absorvidas (Pabs, mmol/dia) foram calculadas a partir da excreção de derivados de purinas na urina (DP, $\mathrm{mmol} / \mathrm{dia})$, pela equação: $\mathrm{DP}=$ $0,85^{*}$ Pabs $+0,385^{*} \mathrm{PC}^{0,75}$, em que 0,85 é a recuperação de purinas absorvidas como derivados urinários de purinas e 0,385* PC ${ }^{0,75}$, a contribuição endógena na excreção urinária de purinas (Verbic et al., 1990).

O fluxo intestinal de compostos nitrogenados microbianos (Nmic, gN/dia) foi calculado em função das purinas microbianas (Pabs, mmol/dia), utilizando-se a equação: Nmic $=(70 *$ Pabs $) /(0,83 * 0,116 * 1000)$, em que 70 representa o conteúdo de $\mathrm{N}$ nas purinas (mg $\mathrm{N} / \mathrm{mmol}$ ), 0,83 a digestibilidade das purinas microbianas e 0,116 a relação $\mathrm{N}$ purina: $\mathrm{N}$ total dos microrganismos ruminais (Chen \& Gomes, 1992).
O experimento foi avaliado considerando-se o grupo de animais como uma amostra aleatória simples, sendo os períodos de avaliação correspondentes às idades crescentes de rebrotação, avaliados como medidas repetidas em cada animal. O procedimento de análise foi conduzido por intermédio do PROC MIXED implementado no pacote estatístico SAS (Statistical Analysis System), utilizando-se matriz de co-variância homogênea (Kaps \& Lamberson, 2004). O efeito de idade de rebrotação foi ortogonalmente decomposto em efeitos de ordens linear, quadrática, cúbica e quártica, com posterior ajuste de regressões lineares. Para todos os procedimentos estatísticos adotou-se $\alpha=0,05$.

Pelos estudos das análises de variância, não se constatou para as variáveis estudadas significância $(\mathrm{P}>0,05)$ para os efeitos de terceiro e quarto graus, sendo estes, portanto, suprimidos da discussão.

\section{Resultados e Discussão}

Verifica-se redução linear no consumo de MS com o aumento da idade de rebrotação do capim-elefante (Tabela 2). Os consumos de MO, PB, FDNcp e CNFcp apresentaram efeito quadrático, fato possivelmente explicado pela alta umidade em que se encontrava o capim-elefante na primeira idade de rebrotação. A MO, o CNFcp e a FDNcp apresentaram máximos consumos aos 44,43; 51,05 e 60,50 dias de rebrotação, respectivamente. O mínimo consumo de $\mathrm{PB}$ ocorreu aos 94,27 dias de rebrotação do capim.

Apesar de a adição de água "livre” no rúmen ter pouco efeito sobre o consumo, por ser esta rapidamente absorvida e removida, existe uma relação provável entre o teor de água de uma gramínea tropical e seu consumo; ou seja, a retenção de água por efeito esponja exercido pelos componentes estruturais da parede celular da planta consumida pode ter efeito inibitório sobre o consumo (Van Soest, 1994).

Nelson \& Moser (1994) afirmaram que, com o aumento da idade, as gramíneas tropicais apresentam um processo acelerado de diferenciação morfológica, caracterizado por aumento dos tecidos de sustentação presentes na região do caule e redução nos tecidos relacionados ao conteúdo celular, como as folhas. Essa redução na relação folha-caule é responsável pelo aumento nos teores de FDN e pela diminuição de nutrientes como a PB e CNF, causando baixa degradação e lento desaparecimento da digesta no rúmen.

Os baixos níveis de PB ingeridos, com o aumento da idade, foram insuficientes para suprir as exigências dos microrganismos ruminais, comprometendo assim a digestão da fibra e reduzindo o consumo de MS. Nos dois últimos períodos, os níveis de proteína atingiram valores muito baixos (5,32 e 5,18\% na MS), abaixo dos níveis mínimos de 
Tabela 3 - Coeficientes de digestibilidade aparente total dos nutrientes, em função do período de rebrotação

\begin{tabular}{|c|c|c|c|c|c|c|c|c|c|}
\hline Item & \multicolumn{5}{|c|}{ Dias de rebrotação } & EPM & \multicolumn{3}{|c|}{ Valor - $\mathrm{P}^{1}$} \\
\hline & \multicolumn{5}{|c|}{ Digestibilidade aparente total } & & & & \\
\hline $\mathrm{MS}^{2}$ & 71,95 & 69,79 & 63,69 & 60,67 & 56,40 & 1,34 & $<0,0001$ & $<0,0001$ & 0,8297 \\
\hline $\mathrm{MO}^{3}$ & 74,76 & 71,47 & 65,14 & 62,62 & 57,54 & 1,24 & $<0,0001$ & $<0,0001$ & 0,9605 \\
\hline $\mathrm{PB}^{4}$ & 75,49 & 66,24 & 65,23 & 51,55 & 47,36 & 1,37 & $<0,0001$ & $<0,0001$ & 0,6548 \\
\hline $\mathrm{CNFcp}^{7}$ & 78,97 & 78,06 & 73,65 & 72,91 & 74,46 & 1,55 & 0,0524 & 0,0123 & 0,1581 \\
\hline $\mathrm{NDT}^{8}$ & 67,16 & 64,22 & 60,20 & 58,47 & 54,66 & 1,13 & $<0,0001$ & $<0,0001$ & 0,9036 \\
\hline
\end{tabular}

${ }^{1}$ Dias = efeito geral do tempo (dias de rebrotação) sobre a variável; $L$ e $Q=$ efeitos de ordem linear e quadrática relativos aos dias de rebrotação; $2 \hat{\mathrm{Y}}=81,39414-0,26818 X\left(r^{2}=0,9839\right) ;{ }^{3} \hat{\mathrm{Y}}=84,49348-0,28869 X\left(r^{2}=0,9867\right) ;{ }^{4} \hat{\mathrm{Y}}=90,96424-0,47288 X\left(r^{2}=0,9489\right) ;{ }^{5} \hat{\mathrm{Y}}=130,511178-1,74217 X+0,0133 X^{2} ;$

${ }^{6} \hat{Y}=83,51072-0,32404 X\left(r^{2}=0,9570\right) ;{ }^{7} \hat{Y}=81,56852-0,09457 X\left(r^{2}=0,6757\right) ;{ }^{8} \hat{Y}=73,85208-0,20496 X\left(r^{2}=0,9897\right)$.

6,25\% PB exigidos na dieta, para adequada digestão pelos microrganismos ruminais (Coelho da Silva \& Leão, 1979).

Valadares et al. (1997), em estudo com animais zebuínos submetidos a dietas com $55 \%$ de feno de capim-elefante contendo 7,$0 ; 9,5 ; 12,0$ ou $14,5 \%$ de $\mathrm{PB}$ verificaram que os consumos de MS e MO foram menores para os animais consumindo a ração com 7,0\% de $\mathrm{PB}$, em relação às demais dietas, que não diferiram entre si.

Observação similar foi feita por Gomes (2004), que trabalhou com diferentes volumosos. Esse autor verificou que, nas dietas com volumoso apenas, o pré-secado de capim-tifton 85 apresentou consumo de MS superior, quando comparado ao capim-elefante e ao feno de capimbraquiária. $\mathrm{O}$ autor atribuiu este comportamento, em parte, ao maior teor de PB do pré-secado de capim-tifton 85 (16,97\%), em relação aos do capim-elefante $(8,53 \%)$ e do feno de capim-braquiária (5,65\%).

Com o aumento da idade, houve também elevação nos teores de FDN indigestível (23,95; 25,69; 32,17; 33,02 e $38,31 \%$, respectivamente, para as idades de 33, 48, 63, 78 e 93 dias), o que também pode ter contribuído para diminuição do consumo de MS.

A diminuição no consumo de NDT deve ter sido causada pela redução no consumo de MS. O consumo de FDNcp, em \%PC, foi próximo de 1,2, valor sugerido por Mertens (1992), a partir do qual o consumo seria limitado por mecanismos físicos para vacas de leite.

Houve redução linear das digestibilidades totais de MS, MO, PB e FDNcp, em função das idades de rebrotação (Tabela 3). Com relação à digestibilidade aparente total do EE, observou-se comportamento quadrático decorrente das variações comumente encontradas neste nutriente, por representar fração pequena em se tratando de gramíneas tropicais. A redução da digestibilidade dos nutrientes deve-se, principalmente, à diminução do teor protéico da dieta e ao aumento dos teores de FDN e FDA indigestíveis e de lignina.

A digestão de MS, MO, FDNcp e CNFcp ocorreu em maior extensão no rúmen (Tabela 4).

As digestibilidades foram expressas em \% do total digestível, com exceção da PB e do EE, que foram expressas em \% da quantidade que chegou em cada local.

As digestibilidades aparentes ruminais da MS e MO apresentaram aumentos lineares em função das idades de rebrotação, provavelmente, em virtude de maior tempo de retenção da digesta neste compartimento do trato gastrintestinal. Deve-se ressaltar que, com o aumento da maturidade, houve redução no consumo de MS e, possivelmente, também na taxa de passagem. Os valores negativos de digestibilidade ruminal da PB a partir dos 48 dias de rebrotação indicam deficiência de proteína degradada no rúmen. Valores negativos para os coeficientes de digestibilidade aparente do EE no rúmen foram observados para todas as idades, indicando síntese de lipídeos microbianos.

Não foi verificada influência das idades de rebrotação sobre as digestibilidades aparentes no rúmen e intestino delgado da FDNcp e dos CNFcp, cujo comportamento para a digestibilidade ruminal da FDNcp pode ser explicado pelo consumo constante desse nutriente em todas as idades de rebrotação avaliadas.

Os demais coeficientes de digestibilidade no intestino delgado, com exceção da FDNcp e dos CNFcp, foram influenciados pelos tratamentos, apresentando redução linear com o aumento da idade do capim-elefante (Tabela 4).

A digestibilidade da FDNcp nos intestinos apresentou valor médio de 8,23\%, porém Rennó (2003) encontrou valor ainda mais baixo (4,13\%). Os valores de digestibilidade intestinal da FDN são baixos, visto que o local de maior digestão deste nutriente é o rúmen. 
Os derivados de purinas estimados apresentaram composição média de 90,32\% de alantoína e 9,67\% de ácido úrico (Tabela 5). Esta relação foi inferior à citada por Verbic et al. (1990), de 85\% de alantoína e 15\% de ácido úrico. Leão et al. $(2004,2005)$ relataram valor médio de 87,90\%; Gomes (2004), de 85,21\%; e Rennó et al. (2000), de 87,17\% para proporção de alantoína. Os valores encontrados neste trabalho foram próximos aos de 91,93; 91,75; 93,13 e 91,79\% de alantoína, relatados por Rennó (2003), Chizzotti et al. (2005, 2006) e Barbosa et al. (2006), respectivamente.

A excreção dos derivados de purinas, as purinas microbianas absorvidas e os compostos nitrogenados microbianos sofreram redução linear com o aumento da idade de rebrotação do capim-elefante.

Em relação aos outros períodos, a média de idade de 93 dias de rebrotação apresentou os menores valores de purinas absorvidas e de compostos nitrogenados microbianos. Os baixos valores obtidos com plantas de 93 dias de rebrotação refletem os baixos teores de PB e NDT da planta nesta idade de crescimento. Infere-se que as variações observadas nos valores de purinas absorvidas e de compostos nitrogenados entre as idades de rebrotação foram evidentes em razão de as concentrações de proteína e energia serem muito diferentes nas idades avaliadas.

Tabela 4 - Digestibilidades ruminal e intestinal dos nutrientes, em função do período de rebrotação

\begin{tabular}{|c|c|c|c|c|c|c|c|c|c|}
\hline Item & \multicolumn{5}{|c|}{ Dias de rebrotação } & EPM & \multicolumn{3}{|c|}{ Valor $-\mathrm{P}^{1}$} \\
\hline & \multicolumn{5}{|c|}{ Digestibilidade aparente ruminal } & & & & \\
\hline $\mathrm{MS}^{2}$ & 55,49 & 61,31 & 60,19 & 61,80 & 64,42 & 2,10 & 0,0526 & 0,0090 & 0,6007 \\
\hline $\mathrm{MO}^{3}$ & 69,60 & 69,64 & 71,23 & 73,85 & 76,67 & 1,87 & 0,0413 & 0,0039 & 0,3013 \\
\hline $\mathrm{PB}^{4}$ & 10,89 & $-9,08$ & $-13,80$ & $-57,64$ & $-50,40$ & 5,50 & $<0,0001$ & $<0,0001$ & 0,5020 \\
\hline $\mathrm{EE}^{5}$ & $-127,08$ & $-37,92$ & $-13,44$ & $-47,22$ & $-9,11$ & 10,48 & $<0,0001$ & $<0,0001$ & 0,0025 \\
\hline CNFcP & \multicolumn{5}{|c|}{ Digestibilidade aparente intestinal } & & & & \\
\hline $\mathrm{MS}^{6}$ & 44,51 & 38,69 & 39,81 & 38,20 & 35,58 & 2,10 & 0,0526 & 0,0080 & 0,6007 \\
\hline $\mathrm{MO}^{7}$ & 30,41 & 30,37 & 28,77 & 26,15 & 23,33 & 1,87 & 0,0413 & 0,0039 & 0,3013 \\
\hline $\mathrm{PB}^{8}$ & 72,42 & 68,99 & 69,35 & 69,15 & 64,77 & 1,44 & 0,0598 & 0,0099 & 0,6818 \\
\hline
\end{tabular}

1 Dias = efeito geral do tempo (dias de rebrotação) sobre a variável; $L$ e $Q$ = efeitos de ordem linear e quadrática relativos aos dias de rebrotação ${ }^{2} \hat{Y}=52,93564+0,12232 X\left(r^{2}=0,7868\right) ;{ }^{3} \hat{Y}=64,4804+0,12245 X\left(r^{2}=0,9114\right) ;{ }^{4} \hat{Y}=47,86848-1,14089 X\left(r^{2}=0,8684\right) ;{ }^{5} \hat{Y}=-142,14790+1,51103 X\left(r^{2}=0,5672\right) ;$ ${ }^{6} \hat{Y}=47,06454-0,12231 X\left(r^{2}=0,7869\right) ;{ }^{7} \hat{Y}=35,51774-0,12245 X\left(r^{2}=0,9114\right) ;{ }^{8} \hat{Y}=75,29822-0,10101 X\left(r^{2}=0,7710\right) ;{ }^{9} \hat{Y}=140,57222-2,09904 X+0,01617 X^{2}$ $\left(r^{2}=0,9198\right)$.

Tabela 5 - Excreções urinárias de alantoína (ALA), ácido úrico (AU) e purinas totais (PT), purinas absorvidas (PA), compostos nitrogenados microbianos (NM), proteína bruta microbiana (PBM), matéria seca microbiana (MSM) e eficiência microbiana (Efic), em função do período de rebrotação

\begin{tabular}{|c|c|c|c|c|c|c|c|c|c|}
\hline \multirow[t]{2}{*}{ Item } & \multicolumn{5}{|c|}{ Dias de rebrotação } & \multirow[b]{2}{*}{ EPM } & \multicolumn{3}{|c|}{ Valor - $\mathrm{P}^{1}$} \\
\hline & 33 & 48 & 63 & 78 & 93 & & Dias & $\mathrm{L}$ & $\mathrm{Q}$ \\
\hline $\mathrm{ALA}^{2 / 6}$ & 124,81 & 120,70 & 120,49 & 97,07 & 71,72 & 9,73 & 0,0045 & 0,0005 & 0,0665 \\
\hline $\mathrm{AU}^{2 / 7}$ & 13,38 & 11,34 & 8,99 & 10,59 & 8,96 & 1,13 & 0,0266 & 0,0062 & 0,1893 \\
\hline $\mathrm{PT}^{3 / 8}$ & 138,19 & 132,04 & 129,48 & 107,66 & 80,67 & 10,03 & 0,0042 & 0,0004 & 0,0974 \\
\hline $\mathrm{PA}^{3 / 9}$ & 103,49 & 96,73 & 93,82 & 71,45 & 44,34 & 9,82 & 0,0033 & 0,0003 & 0,0987 \\
\hline $\mathrm{NM}^{3 / 10}$ & 71,38 & 74,63 & 55,60 & 49,37 & 34,06 & 5,79 & 0,0006 & $<0,0001$ & 0,2186 \\
\hline $\mathrm{PBM}^{3 / 11}$ & 470,26 & 439,55 & 426,35 & 324,67 & 201,47 & 44,61 & 0,0033 & 0,0003 & 0,0986 \\
\hline $\mathrm{MSM}^{3 / 12}$ & 1275,31 & 1156,39 & 1176,46 & 977,81 & 610,57 & 136,97 & 0,0160 & 0,0019 & 0,1393 \\
\hline Efic $^{4 / 13}$ & 15,68 & 14,65 & 14,21 & 10,82 & 6,72 & 1,49 & 0,0033 & 0,0003 & 0,0985 \\
\hline Efic $^{5 / 14}$ & 23,35 & 21,36 & 24,67 & 19,50 & 13,40 & 2,64 & 0,0177 & 0,0058 & 0,0508 \\
\hline
\end{tabular}

1 Dias = efeito geral do tempo (dias de rebrotação) sobre a variável; $\mathrm{L}$ e $\mathrm{Q}=$ efeitos de ordens linear e quadrática relativos aos dias de rebrotação; 2 mmol/dia

${ }^{3} \mathrm{~g} / \mathrm{dia} ;{ }^{4} \mathrm{gN} / \mathrm{kg}$ MODR; ${ }^{5} \mathrm{gPB} / 100 \mathrm{~g}$ NDT $;{ }^{6} \hat{\mathrm{Y}}=161,47930-0,86543 \mathrm{X}\left(\mathrm{r}^{2}=0,8300\right) ;{ }^{7} \hat{\mathrm{Y}}=14,68196-0,06399 \times\left(\mathrm{r}^{2}=0,6785\right) ;{ }^{8} \hat{\mathrm{Y}}=176,16248-0,92943 \mathrm{X}\left(\mathrm{r}^{2}=0,8692\right) ;$ $9 \hat{\mathrm{Y}}=121,13330-0,51683 \mathrm{X}\left(\mathrm{r}^{2}=0,8172\right) ;{ }^{10} \hat{\mathrm{Y}}=98,96898-0,66606 \mathrm{X}\left(\mathrm{r}^{2}=0,9040\right) ;{ }^{11} \hat{\mathrm{Y}}=646,49320-4,34973 \mathrm{X}\left(\mathrm{r}^{2}=0,8779\right) ; 12 \hat{\mathrm{Y}}=1672,69320-10,05373 \mathrm{X}$ $\left(r^{2}=0,8246\right) ;{ }^{13} \hat{Y}=21,5508-0,14500 X\left(r^{2}=0,8778\right) ; 4 \hat{Y}=29,59590-0,14510 X\left(r^{2}=0,6094\right)$. 
A eficiência microbiana (gN/kgMODR), que variou de 23,34 a 13,39 g Nmic/kg MODR, encontra-se abaixo daquela citada pelo ARC (1984), de $32 \mathrm{~g} \mathrm{~N}$ mic/kg MODR. Quando a eficiência foi expressa em g de $\mathrm{PB} / 100 \mathrm{~g}$ de NDT, os valores obtidos para as idades de 33 a 63 dias situaram-se próximos ao valor médio de 13 g de $\mathrm{PB} / 100 \mathrm{~g}$ de NDT, citado pelo NRC (2001).

Gomes (2004) observou diferença significativa entre os volumosos avaliados, encontrando maiores valores de $\mathrm{N}$ microbiano para o pré-secado de capim-tifton 85 e o capim-elefante de 55,69 e 52,73 g, respectivamente, e menor valor para o feno de capim-braquiária, 21,81 g. Os valores de $\mathrm{N}$ microbiano para este experimento variaram de 75,24 a 32,23 g para as idades de 33 e 93 dias de rebrotação, respectivamente.

Trabalhando com dois níveis de PB na ração (12 e 15\%), Rennó (2003) não verificou influência desses níveis na excreção dos derivados de purinas, nas purinas microbianas absorvidas, nos compostos nitrogenados microbianos e na eficiência microbiana.

\section{Conclusões}

Recomenda-se utilizar o capim-elefante (cv. Cameroon) com 30 a 35 dias de rebrotação, visto que nesta idade a planta apresentou os melhores resultados de digestibilidade e parâmetros metabólicos, indicando, assim, maior valor nutritivo.

\section{Literatura Citada}

AGRICULTURAL AND FOOD RESEARCH COUNCIL - AFRC. Energy and protein requirements of ruminants. Wallingford: CAB International, 1993. 159p.

AGRICULTURAL RESEARCH COUNCIL - ARC. The nutrient requirements of ruminant livestock. № 1 . England: 1984. $45 p$.

BARBOSA, A.M.; VALADARES, R.F.D.; VALADARES FILHO, S.C. et al. Efeito do período de coleta de urina, dos níveis de concentrado e de fontes protéicas sobre a excreção de creatinina, de uréia e de derivados de purina e a produção microbiana em bovinos Nelore. Revista Brasileira de Zootecnia, v.35, n.3, p.870-877, 2006.

BRODERICK, G.A.; MERCHEN, N.R. Markers for quantifying microbial protein synthesis in the rumen. Journal of Dairy Science, v.75, n.9, p.2618-2632, 1992.

CHEN, X.B., GOMES, M.J. Estimation of microbial protein supply to sheep and cattle based on urinary excretion of purine derivates - an overview of technical details. Bucksburnd: Rowett Research Institute, International Feed Research Unit, 1992. 21p. (Occasional publication).

CHIZZOTI, M.L.; VALADARES FILHO, S.C.; VALADARES, R.F.D. et al. Casca de algodão em substituição parcial à silagem de capim-elefante para novilhos. Parâmetros ruminais e séricos, produção microbiana e excreção urinária de compostos nitrogenados. Revista Brasileira de Zootecnia, v.34, n.6, p.2103-2111, 2005.
CHIZZOTI, M.L.; VALADARES FILHO, S.C.; VALADARES, R.F.D. et al. Consumo, digestibilidade e excreção de uréia e derivados de purinas em novilhas de diferentes pesos. Revista Brasileira de Zootecnia, v.35, n.4, p.1813-1821, 2006 (supl.).

COELHO DA SILVA, J.F., LEÃO, M.I. Fundamentos de nutrição dos ruminantes. Piracicaba: Livroceres, 1979. 380p.

CONRAD, H.R.; PRATT, A.D.; HIBBS, J.W. Regulation of feed intake in dairy cows. I. Change in importance of physical and physiological factors with increasing digestibility. Journal of Dairy Science, v.47, n.1, p.54-62, 1964.

FUJIHARA, T.; ØRSKOV, E.R.; REEDS, P.J. et al. The effect of protein infusion on urinary excretion of purine derivatives in ruminants nourished by intragastric nutrition. Journal of Agricultural Science, v.109, p.7-12, 1987.

GOMES, S.P. Contaminação salivar da extrusa, consumo, digestibilidade e produção microbiana em novilhos alimentados com diferentes dietas. Viçosa, MG: Universidade Federal de Viçosa, 2004. 56p. Dissertação (Mestrado em Zootecnia) - Universidade Federal de Viçosa, 2004.

HALL, M.B.; LEWIS, B.A.; Van SOEST, P.J. et al. A simple method for estimation of neutral detergent-soluble fibre. Journal of the Science of Food and Agriculture, v.74, n.4, p.441-449, 1997.

KAPS, M.; LAMBERSON, W. Biostatistics for animal science. 7.ed. London: CABI Publishing, 2004. 445p.

LEÃO, M.I. Metodologias de coletas de digestas omasal e abomasal em novilhos submetidos a três níveis de ingestão: consumo, digestibilidade e produção microbiana. Belo Horizonte: Universidade Federal de Minas Gerais, 2002. 57p. Tese (Doutorado em Ciência Animal) Universidade Federal de Minas Gerais, 2002.

LEÃO, M.I.; COELHO DA SILVA, J.F. Técnicas de fistulação de abomaso em bezerros. In: CONGRESSO BRASILEIRO DE ZOOTECNIA, 1., 1980, Fortaleza: Sociedade Brasileira de Zootecnia, 1980. p.37.

LEÃO, M.I.; VALADARES FILHO, S.C.; RENNÓ, L.N. et al. Consumos e digestibilidades aparentes totais e parciais de matéria seca, matéria orgânica, proteína bruta e extrato etéreo em novilhos submetidos a três níveis de ingestão e duas metodologias de coleta de digestas abomasal e omasal. Revista Brasileira de Zootecnia, v.33, n.6, p.1604-1615, 2004.

LEÃO, M.I.; VALADARES FILHO, S.C.; RENNÓ, L.N. et al. Consumos e digestibilidades aparentes totais e parciais de carboidratos totais, fibra em detergente neutro e carboidratos não fibrosos em novilhos submetidos a três níveis de ingestão e duas metodologias de coleta de digestas abomasal e omasal. Revista Brasileira de Zootecnia, v.34, n.2, p.670-678, 2005.

MERTENS, D.R. Análise da fibra e sua utilização na avaliação de alimentos e formulação de rações. In: SIMPÓSIO INTERNACIONAL DE RUMINANTES, 1992, Lavras. Anais... Lavras: Sociedade Brasileira de Zootecnia, 1992. p.188-219.

MERTENS, D.R. Regulation of forage intake. In: FAHEY JR., G.C. (Ed.) Forage quality, evaluation and utilization. American Society of Agronomy. NATIONAL CONFERENCE ON FORAGE QUALITY, EVALUATION AND UTILIZATION. Madison: American Society of Agronomy, 1994. p.450-493.

NATIONAL RESEARCH COUNCIL - NRC. Nutrient requirements of dairy cattle. 6.ed. Washington, D.C.: National Academic Press, 1989. 158p.

NATIONAL RESEARCH COUNCIL - NRC. Nutrient requeriments of dairy cattle. 7.ed. Washinton, D.C.: National Academic Press, 2001. 381p.

NELSON, C.J.; MOSER, L.E. Forage quality, evaluation, and utilization. Madison: Library of Congress, 1994. p.112-134.

PELL, A.N.; SCHOFIELD, P. Computerized monitoring of gas production to measure forage digestion in vitro. Journal of Dairy Science, v.76, p.1063-1073, 1993.

PEREZ, J.F.; BALCELLS, J.; GUADA, J.A. et al. Determination of rumen microbial nitrogen production in sheep: a comparison 
of urinary purine excretion with methods using ${ }^{15} \mathrm{~N}$ and purine bases as markers of microbial-nitrogen entering the duodenum. British Journal of Nutrition, v.75, n.5, p.699-709, 1996.

RENNÓ, L.N.; VALADARES, R.F.D.; LEÃO, M.I. et al. Estimativa da produção de proteína microbiana pelos derivados de purinas na urina em novilhos. Revista Brasileira de Zootecnia, v.29, p.1223-1234, 2000.

RENNÓ, L.N.; VALADARES FILHO, S.C.; PAULINO, M.F. et al. Indicadores interno ou externo e efeito da contaminação da fibra em detergente neutro sobre a digestibilidade aparente total em novilhos. In: REUNIÃO ANUAL DA SOCIEDADE BRASILEIRA DE ZOOTECNIA, 39., 2002, Recife. Anais... Recife, 2002. (CD-ROM).

RENNÓ, L.N. Consumo, digestibilidade total e parcial, produção microbiana, parâmetros ruminais e excreções de uréia e creatinina em novilhos alimentados com dietas contendo quatro níveis de uréia ou dois níveis de proteína. Viçosa, MG: Universidade Federal de Viçosa, 2003. 252p. Tese (Doutorado em Zootecnia) - Universidade Federal de Viçosa, 2003.

RUSSELL, J.B.; O'CONNOR, J.D.; FOX, D.J. et al. A net carbohydrate and protein system for evaluating cattle diets: I. Ruminal fermentation. Journal of Animal Science, v.70, n.11, p.3551-3561, 1992.
SILVA, D.J.; QUEIROZ, A.C. Análise de alimentos (métodos químicos e biológicos). 3.ed. Viçosa, MG: Editora UFV, 2002. 235p.

UNIVERSIDADE FEDERAL DE VIÇOSA - UFV. SAEG - Sistema de análises estatísticas e genéticas. Versão 7.1. Viçosa, MG, 1997. 150p. (Manual do usuário).

VALADARES, R.F.D.; GONÇALVES, L.C.; RODRIGUEZ, N.M. et al. Níveis de proteína em dietas de bovinos. 4. Concentrações de amônia ruminal e uréia plasmática e excreções de uréia e creatinina. Revista Brasileira de Zootecnia, v.26, n.6, p.1270-1278, 1997.

Van SOEST, P.J. Nutritional ecology of the ruminant. 2.ed. London: Comstock Publishing Associates, 1994. 476p.

VERBIC, J.; CHEN, X.B.; MACLEOD, N.A. et al. Excretion of purine derivatives by ruminants. Effect of microbial nucleic acid infusion on purine derivative excretion by steers. Journal of Agricultural Science, v.114, n.3, p.243-248, 1990.

VIEIRA, P.F. Efeito do formaldeído na proteção de proteínas e lipídios em rações para ruminantes. Viçosa, MG: Universidade Federal de Viçosa, 1980. 98p. Tese (Doutorado em Zootecnia) - Universidade Federal de Viçosa, 1980.

WEISS, W.P. Energy prediction equations for ruminant feeds. In: CORNELL NUTRITION CONFERENCE FOR FEED MANUFACTURERS, 61., 1999, Ithaca. Proceedings... Ithaca: Cornell University, 1999. p.176-185. 